\title{
FIGURAS DE LA ANTIPOLÍTICA EN CARL SCHMITT
}

Rodrigo Páez Canosa* rpc@sud.com.ar

RESUMO El presente trabajo desarrolla distintas figuras que Carl Schmitt señala comoformas de subjetividad antipolitica. Sidesde la perspectiva del jurista alemán las operaciones que constituyen un modo de ser político son aquellas que producen o sostienen una forma representativa, lo propio de una subjetividad antipolitica son aquellas operaciones que erosionan o conducen a la destrucción de dicha forma politica. El trabajo intenta mostrar que la operación fundamental en este sentido es la dilación, entendida como la postergación indefinida de la decisión. Así, bajo las diversas figuras de la antipolitica que Schmitt aborda, esta operación también adquiere diversas formas de aparición: en el caso de la subjetividad liberal se da bajo la forma de la discusión y el compromiso, en el caso del romántico político bajo la forma de la poetización.

Palavras-chave Carl Schmitt, subjetividad antipolitica, liberalismo, romanticismo.

ABSTRACT This paper develops various figures noted by Carl Schmitt as forms of anti-political subjectivity. Whereas, from the German jurist's perspective, the operations which constitute a political way of being are those which produce and care for a representative form, the specificity of a antipolitical subjectivity is shaped by those operations which erode or wear that political form down. The paper aims to show that the main feature of the

* Professor da Universidad de Buenos Aires e Pesquisador do CONICET. Artigo recebido em agosto de 2008 e aprovado em novembro de 2008.

KRITERION, Belo Horizonte, nº 118, Dez./2008, p. 379-400. 
antipolitical way of being is the delay, meaning the indefinite postponement of the decision as such. Thus, under the various figures of the anti-politics that Schmitt deals with, this operation appears on different manners: the liberal form of postponing is the endless discussion and the compromise; the romatic form is the aesthetization of the world.

Key-words Carl Schmitt, anti-political subjectivity, liberalism, romanticism.

Diferir es la operación más propia de toda subjetividad antipolítica. Sin atender a las condiciones en las que se despliega, ella rechaza toda resolución, a la que concibe como una afrenta o, más aún, como una amenaza. Porque la decisión no es una acción más, molesta y desagradable, sino que ella se constituye en esa dilación y todo corte, en tanto punto final de la demora, la destruye. El carácter antipolítico de la dilación se expresa de un modo concreto en las situaciones de crisis, ${ }^{1}$ pues ahí se percibe claramente que el aplazamiento indefinido de la decisión conduce indefectiblemente a la simple disolución del orden amenazado. Si frente a la crisis existe algún gesto o la producción de un mínimo de forma, entonces ya operó allí algún corte capaz de instituir coordenadas básicas para la acción. En estos casos se revela el núcleo metafísico de toda subjetividad antipolítica que, a través de diversas operaciones, se constituye en oposición a toda acción formativa: ella es ante todo socavamiento de forma y representación. No se trata en efecto de que toda subjetividad antipolítica sea destructiva de un modo militante ni de que pueda existir sólo en un medio caótico. Por el contrario, tanto el liberal como el romántico como figuras de la antipolítica sólo pueden desplegarse al resguardo de un orden político estable. Pero las operaciones que los constituyen se oponen a aquellas que producen orden político, forma y representación. Su acción no es pues destructiva de un modo directo, sino erosiva y deconstructiva.

El pensamiento de Schmitt desarrolla esta subjetividad antipolítica a través de distintas figuras que le permiten comprender las operaciones específicas que la constituyen y el peligro político que entraña. Desde un punto de vista ligado a una situación concreta de conflicto que precisa de una

1 La fuerza explicativa del momento excepcional es una de las premisas del abordaje schmittiano de los conceptos políticos. En efecto, «Lo normal no prueba nada, la excepción prueba todo; no sólo confirma la regla, la regla vive en verdad sólo de la excepción» (Schmitt 1922: 21). 
decisión, el rechazo de esta subjetividad a toda determinación sólo agudiza las dificultades presentes y conduce en última instancia a la disolución del orden amenazado. Las dificultades que afrontó la República de Weimar a lo largo de toda su existencia, sus causas y el modo en que se disolvió fueron para Schmitt expresiones claras de los efectos de la indeterminación en el campo de la política. Su participación directa en las disputas teóricas y políticas de Weimar le permitió una comprensión amplia y profunda del modo en que la indeterminación se expresó en todas las instancias decisivas: tanto en la Constitución, ${ }^{2}$ como en las doctrinas prevalecientes que marcaban el rumbo, ${ }^{3}$ como también en las resoluciones concretas que (no) se tomaron. ${ }^{4} \mathrm{La}$ Segunda Guerra y el orden mundial que se estableció tras ella mostraron sin matices los peligros que contenía. Es característico del abordaje schmittiano apuntar directamente al núcleo de la cuestión. No se pierde en rodeos, sino que piensa las operaciones que constituyen a la subjetividad antipolítica en su núcleo metafísico: bajo sus diversas formas, la dilación que constituye a la subjetividad antipolítica se manifiesta en un tránsito perpetuo y una fuente inagotable de simple pluralidad indiferenciada. Esta fluidez y apertura la vuelve muy productiva en las esferas de la economía y la estética, pero se constituye como un serio obstáculo para la construcción política. Este rasgo nodal de la subjetividad antipolítica se manifiesta de diversas maneras. En primer lugar se desarrollará aquí la figura del romanticismo, a partir de la cual Schmitt polemiza con una de las caras del yo moderno: aquella que asume la secularización de la omnipotencia divina como un modo de afirmación de la propia omnipotencia, entendida como una inquieta y permanente autoproducción de sí. De allí que toda definición, toda forma y construcción que se objetive y estabilice de alguna manera en el mundo sea vista como un agravio a su productividad infinita. En segundo término se tratará las formas liberales de aparición de la subjetividad antipolítica. Si bien el liberalismo es un antagonista permanente del pensamiento de Schmitt, es posible distinguir algunos matices en su caracterización. En ese sentido, interesa aquí destacar dos operaciones centrales de la subjetividad liberal que, aunque íntimamente relacionadas, destacan en cada caso aspectos diversos. Esas operaciones son la discusión y el compromiso.

2 Para Schmitt la Constitución de Weimar no era expresión de una decisión unitaria, sino el fruto de un acuerdo. De allí la mezcolanza de principios (socialistas, liberales, católicos, etc.) que contiene y la escisión profunda entre la primera y la segunda parte. Ver Schmitt 1928a: 52-57; Schmitt 1932c: 57-79.

3 Fundamentalmente el parlamentarismo de corte liberal. Ver Schmitt 1923a.

4 La referencia es aquí a la negativa del presidente Hindenburg a establecer una dictadura en defensa de la Constitución y la consiguiente designación de Adolf Hitler como Canciller en 1933. 
1. El principal desarrollo schmittiano del núcleo metafísico de la subjetividad antipolítica se encuentra en Romanticismo político de 1919. En el prólogo a la segunda edición de 1924 Schmitt hace una suerte de aclaración metodológica central que no sólo instituye la perspectiva de análisis que había seguido en el trabajo de 1919 sino que, además, es posible extender como clave de lectura para el abordaje de la cuestión de la subjetividad a lo largo de toda su obra. Después de señalar como insuficientes las definiciones por temáticas o caracterizaciones dice:

...la definición del romanticismo no puede partir de cualquier objeto o tema percibido como romántico, de la Edad Media o de las ruinas, sino del sujeto romántico. Siempre se dará con una determinada clase de personas, lo que en el plano intelectual es evidente. Se debe atender a la conducta particular del romántico y a partir de la relación específicamente romántica con el mundo, no del resultado de esta conducta ni de todas las cosas y circunstancias que aparecen en una colorida variedad como consecuencias o síntomas (Schmitt 1919: 43).

Son las operaciones del sujeto romántico, su modo de estar y relacionarse con el mundo lo que revela su núcleo metafísico. Desde esta perspectiva, el estudio del romanticismo se revela como un estudio de la subjetividad romántica. Lo que Schmitt indaga no es una descripción empírica ni una caracterización del sentido común. Al investigar los modos de estar concretos, precisa las operaciones que constituyen un sujeto como sujeto romántico. Como se verá más adelante, la misma perspectiva puede ser adoptada respecto del liberal como figura de la antipolítica: apunta fundamentalmente a definir las operaciones que constituyen al sujeto liberal. Es decir, antes que describir a aquellas personas, acontecimientos o movimientos llamados románticos o liberales, Schmitt define políticamente aquello que hace a un liberal, liberal y a un romántico, romántico.

En este último caso, el abordaje de Schmitt interviene en distintos registros a la vez. Por un lado, intenta impugnar conceptualmente la inclusión de los contrarrevolucionarios y la Iglesia Católica en el movimiento romántico. ${ }^{5}$ La estrategia central para ello no consiste en la exposición de evidencias históricas, sino en el señalamiento de las diferencias sujetivas esenciales que los distinguen. En efecto, si no es posible dicha inclusión es porque la relación que los reaccionarios y la Iglesia Católica establecen con el mundo difiere de aquella de los románticos en su núcleo conceptual: mientras que estos últimos permanecen ajenos a todo posicionamiento que suponga una incursión en la 
realidad política concreta, aquellos constituyen su pensamiento y su praxis como un modo de intervención directo. Por otro lado, la comprensión de la subjetividad romántica en su núcleo metafísico es una tarea de primer orden en la medida en que no refiere a una subjetividad extraña, sino a un modo de darse del «espíritu moderno». El peligro que representa para todo orden político no es un peligro que amenaza desde fuera. Como señala Carlo Galli, Schmitt y los románticos - podría decirse: el pensamiento moderno en general - tienen el mismo punto de partida: la desustancialización de la realidad que ya no presenta una estructura esencialista. ${ }^{6}$ La actividad sintética del sujeto se vuelve así una instancia fundamental en la constitución moderna del mundo. Pero, ante ese común punto de partida los caminos se bifurcan ya que lo que constituye una $u$ otra forma de subjetividad no es el reconocimiento de ese «fondo abismal» sino el modo de habitar esa nueva realidad que surge en la modernidad. Así, mientras que la subjetividad romántica exacerba la productividad del sujeto de modo tal que rechaza toda detención de su actividad poiética auto-referencial y así toda cristalización de la misma, Schmitt persigue una «voluntad de forma» ${ }^{7}$ que se expresa en una objetivación visible de la actividad productiva del sujeto. Este es el punto decisivo que distingue hacia dentro del «espíritu moderno» una y otra posición. Porque aún cuando ambos se encuentran inscriptos en el moderno proceso de secularización, las distintas formas en que se da ese proceso produce efectos filosófico-políticos muy distintos: una cosa es «cuando se pone en el lugar de Dios a otra instancia objetiva absoluta, por ejemplo, el Estado, [en ese caso] aún es posible una cierta objetividad y sujeción» (Schmitt, 1919: 59). Pero,

que la instancia última se desplace de Dios al «yo» genial cambia todo el primer plano y revela el ocasionalismo en forma auténtica y pura. [...]. Porque ésta [postura] hace posible tomar cualquier punto concreto como salida para vagar por lo ilimitado e inconcebible a partir de él, según la individualidad del individuo romántico [...]. A partir de oportunidades siempre nuevas se origina un mundo siempre nuevo, pero sólo ocasional, un mundo sin sustancia, sin sujeción funcional, sin conducción firme, sin conclusión, sin definición, sin decisión, sin tribunal último, que sigue su curso infinitamente conducido por la mano mágica del azar, the magic hand of chance (Schmitt 1919: 59-60).

La pura productividad no puede someterse sin destruirse, de allí el carácter esencial de su antipoliticidad. 
Las distintas notas que Schmitt señala de la subjetividad romántica remiten siempre al punto nodal que la distinguen de la propia posición del jurista: la imposibilidad de una representación formativa. Según la definición distintiva de Schmitt el romanticismo es «ocasionalismo subjetivado» (Schmitt 1919: 58, 163-164). Con esta fórmula expresa la relación específica del sujeto romántico con el mundo: éste es sólo una ocasión y una oportunidad para el despliegue poiético de aquél. Se vuelve así creador del mundo, ya que para él sólo será mundo lo que sirva de ocasión para una vivencia propia. Este endiosamiento del sujeto - propio de la sociedad burguesa - permite captar con claridad el efecto disolvente de su actividad: todo acontecimiento externo le es indiferente porque, más allá de su gravedad o superficialidad, cualquiera puede servir de punto de partida para la actividad creadora del sujeto. Una guerra mundial, un desengaño amoroso o el movimiento de un molino pueden ser todos por igual ocasión para la poetización romántica. Esta indiferencia vuelve fútil toda intervención en el mundo y se expresa, llevada al plano subjetivo, en una aversión hacia los conflictos externos característica de los románticos. El envés antipolítico de esta actitud es la «reserva subjetivista» (Schmitt 1919: 135) que no sólo mantiene al romántico apartado de la realidad, sino que lo conduce a rechazar toda concretización efectiva de la acción. Frente al yo productor de la realidad moderna, el yo romántico prefiere el eterno errar sin dirección fija. En efecto, toda realización concreta es la destrucción del pleno infinito de posibilidades. Mientras que lo posible es un espacio fértil para aquel vagabundeo, transformar lo real es siempre una actividad mezquina. Así, con vistas a la preservación de su excitada creatividad los románticos convierten la posibilidad en una categoría más digna y más «real» que la realidad misma.

Esta opción por la posibilidad sustrae a la subjetividad romántica de toda definición y le constituye una línea de escape, un refugio al cual retirarse si apremia la necesidad de actuar. Mediante operaciones específicas evade siempre la responsabilidad de una resolución. Pero ¿Cuáles son esas operaciones que le permiten diferir indefinidamente la decisión? Schmitt señala la ironía y la intriga como los procedimientos propios de la subjetividad romántica:

El romántico evita la realidad, pero irónicamente y con ánimo de intriga. Ironía e intriga no son disposiciones de ánimo de un hombre en fuga, sino la actividad de un hombre que, en lugar de crear nuevas realidades, hace jugar una contra otra para paralizar la realidad limitada que en cada caso se presenta. El romántico se sustrae irónicamente a la objetividad opresiva y se guarda de comprometerse con cualquier cosa; en la ironía se encuentra la reserva de todas las posibilidades infinitas. Así preserva su genial libertad interior, la cual consiste en no renunciar a ninguna posibilidad (Schmitt 1919: 134). 
Para Schmitt, en primer lugar, la ironía no es utopía. La operación utópica consiste en crear una realidad abstracta que sirva de criterio para juzgar la realidad concreta, pero en sí misma carece de realidad. El romántico, por el contrario, no crea realidades nuevas, sino que toma las existentes y las hace jugar de modo tal que se neutralicen y no haga falta intervenir en ellas. Frente a un conflicto concreto la ironía permite disolver la oposición de las partes en un «tercero superior» en el que se armonizan. Puede ser el Estado, la Iglesia o cualquier otro. En el caso de que aquel tercero neutralizador entre en conflicto, siempre será posible encontrar uno nuevo que neutralice al anterior. Es por ello que la decisión destruye la subjetividad romántica. Lo que la mantiene en su ser es, por el contrario, la dilación perpetua de la decisión que se sostiene en la operación de disolución de los conflictos a partir de la apelación al «tercero superior» que se constituye siempre como «la escapatoria ante la disyuntiva radical» (Schmitt 1919: 183).

Cuando esta operación de fuga se despliega sobre la actividad política se constituye como irresponsabilidad. Por un lado porque su carácter pasivo y prescindente la pone al servicio de cualquier fuerza externa a sí misma. Si ella no decide, otros decidirán por ella y la sumarán como parte de una intervención concreta, más allá de las reservas y excusas que interponga. Pero sobre todo porque en el campo político la dilación de la decisión produce caos y disolución. Schmitt insiste en el final de Romanticismo político en la oposición extrema entre la subjetividad romántica y la política. Pero esta oposición no refiere fundamentalmente a que el romántico político no sea un personaje efectivo en la política, sino al hecho de que, en su límite, una destruye a la otra. Si sólo afirmase la ineficacia política del romántico, no habría mayor problema: los románticos políticos serían unos personajes pintorescos que pasarían de una fuerza política a otra, redactando con alto estilo distintos programas sin importar su contenido. Pero la cuestión es más profunda y atañe al núcleo metafísico. La actividad política destruye al romanticismo porque lo determina y la neutralización romántica de la decisión socava todo orden en la medida en que impide la institución de una forma representativa, siempre fundada para Schmitt en un corte decisivo. De hecho, el romanticismo político como tal no existe; Schmitt llama así al «acompañamiento emotivo del romántico a un suceso político, que provoca ocasionalmente una productividad romántica» (Schmitt 1919: 239). Al señalar esta incompatibilidad, Schmitt indica el peligro que entraña para todo orden político el giro subjetivista de la secularización moderna que desplaza la omnipotencia divina hacia el yo. En ese sentido, la subjetividad romántica realiza en clave estética la operación burguesa de elevar la dimensión privada a fundamento último. El yo cerrado en sí mismo 
sirve ahora como criterio de acción y de pensamiento. Constituido a partir de una exaltada productividad artística, la subjetividad romántica lleva su operación de neutralización estética también a todas las dimensiones de la vida práctica:

La estetización general - considerada sociológicamente - sólo sirvió para privatizar por la vía de lo estético también los otros campos de la vida espiritual. Si se disuelve la jerarquía de la esfera espiritual, todo puede convertirse en centro de la vida espiritual. Pero todo lo relacionado con el espíritu, incluso también el arte, se transforma en su esencia, y hasta se falsea, cuando lo estético es absolutizado y puesto como centro. [...]. Ni las decisiones religiosas, ni las morales, ni las políticas, ni los conceptos científicos son posibles en el terreno de lo puramente estético. Pero ciertamente, todas las contradicciones y diferencias objetivas, bien y mal, amigo y enemigo, Cristo y Anticristo, pueden convertirse en contrastes estéticos... (Schmitt 1919: 57).

Esto es lo que hace el romántico y lo que lo vuelve destructivo para la política, sólo posible a partir de tales decisiones. Como pensador de la autonomía de lo político, Schmitt no impugna la actividad romántica en sí, sino el desplazamiento de lo estético a lo político y el debilitamiento de los criterios específicos de este último ámbito que trae consigo. Schmitt no se opone, sin embargo, a la estetización de lo político desde una exigencia abstracta de pureza. Por el contrario, lo que el jurista señala es el peligro político que entraña la irresponsabilidad romántica. Al situarse en una posición pasiva que observa y acompaña, el romanticismo se pone «al servicio de otras energías no románticas y la elevación sublime por sobre la definición y la decisión se transforma en una compañía servil de fuerzas ajenas y de decisiones ajenas» (Schmitt 1919: 242).

2. La crítica de Schmitt al liberalismo no es una crítica, se trata más bien de una oposición polémica. Sobre todo por las implicancias subjetivas de la crítica: ella es una operación con una fuerte impronta liberal. En efecto, Schmitt no busca develar las injusticias que el liberalismo oculta, ni discutir indefinidamente al respecto, sino posicionarse frente a él como católico en el plano teológico, como decisionista en el plano jurídico y como estatalista en el plano político; es decir, no crítica, sino existencialmente. ${ }^{8}$ Esta oposición sin embargo no impide cierta oscilación en sus planteos. Muchas veces de hecho parece no quedar claro cuál es precisamente el objeto de la polémica ni la oposición misma: ¿Es el parlamentarismo de Weimar lo mismo que el

8 Maschke 1988: 73. El contraste con la perspectiva liberal es bien clara: mientras que el libro que contiene el artículo de Maschke, cuyos compiladores se reconocen liberales ellos mismos, refiere en su título a la «crítica del liberalismo» de Schmitt, Maschke, que se denomina a sí mismo anti-liberal, entiende la posición de Schmitt frente al liberalismo como una oposición y no como una crítica. 
liberalismo? ¿Son antiliberales las dictaduras comisariales y las presidencias fuertes o son más bien medidas extremas que permiten el resguardo de un orden liberal? ¿Por qué la cuestión de la propiedad privada - uno de sus aspectos fundamentales - no es un punto central en la oposición schmittinana al liberalismo ${ }^{9}$ En verdad, en concordancia con la perspectiva tomada en su estudio sobre el romanticismo, gran parte de su abordaje polémico del liberalismo apunta a desentrañar el «espíritu» del liberalismo, es decir, el núcleo metafísico de la subjetividad liberal. Antes que ver las medidas que tomaron o toman los gobiernos llamados liberales, Schmitt busca delimitar las operaciones constitutivas del sujeto liberal para luego reconocer los aspectos liberales o no de los distintos acontecimientos y movimientos políticos («liberales» o no) que aborda. En ese sentido no son incoherentes con su antiliberalismo ni su participación en la defensa del Reich (supuestamente liberal) contra Prusia, ${ }^{10}$ ni el intento de sostener la Constitución de Weimar a partir de su interpretación del art. 48, ${ }^{11}$ ni sus elogios o acercamientos teóricos a grandes nombres de la tradición liberal como Jacob Burckhardt o Bejamin Constant. ${ }^{12}$ En todos los casos lo que rescata son los elementos no-liberales de todos esos compromisos - intelectuales y políticos - que asume. Es parte de su perspectiva antiliberal, justamente, no reducir toda explicación al individuo. En ese sentido, no todo lo que dice un hombre liberal como el pensador francés es liberal, por el contrario, un mismo hombre porta siempre diversas máscaras. Así, la teoría del pouvoir neutre parece situarse, al menos en su interpretación, del lado de un pensamiento político no liberal y cubre al nombre Constant con una máscara estatalista. Por otra parte, es propio del antiliberalismo de Schmitt sostener (en toda la amplitud del término) las concepciones e instituciones que en una situación política conflictiva conduzcan al mantenimiento del orden político. En ese sentido, más allá de las insuficiencias que encuentra en la Constitución de Weimar, es coherente que haya tomado partido por ella hasta el momento mismo de su derrumbe y que lo haya hecho subrayando insistentemente sus elementos no liberales. Porque, sin descuidar en nada la rigurosidad de sus ideas, Schmitt no desconoce el carácter político - i.e. polémico - de las mismas y las particularidades que se siguen de este reconocimiento: en primer lugar, que no se trata de realizar una descripción empírica de los gobiernos y las teorías

9 Sobre la cuestión de la propiedad como principio del liberalismo ver Schmitt 1928a: 299; Schmitt 1932a: 99.

10 Sobre esta cuestión véase Schmitt 1932b; Bendersky 1983: 154-167.

11 Véase, entre otros, Schmitt 1925; Schmitt 1931: 132-159.

12 Para la figura de Jacob Burkchardt véase Schmitt 1932a: 54; Schmitt 1928a: 103. Sobre Constant véase Schmitt 1925: 26, Schmitt 1931: 132 y ss. Véase también Dotti: 2005. 
liberales, sino de conceptualizar su principio existencial. En segundo lugar, que esa conceptualización no es neutral, sino que supone un posicionamiento político. No es lo mismo, en efecto, entender que el liberalismo es ante todo neutralización de la decisión que defensa de la propiedad privada; y la elección de una u otra definición no nace de un análisis pretendidamente objetivo de cierto corpus liberal (i¿Cómo se delimita el corpus si no se ha tomado ya partido?!), sino de una decisión respecto de los actores e ideas concretas que intervienen en una situación política concreta.

En el contexto de una profunda inestabilidad política como la del período de entreguerras en Alemania, cuestiones como la libertad o la división de poderes, ambas constitutivas del liberalismo, eran a los ojos de Schmitt secundarias respecto de la cuestión nodal de la época. ${ }^{13}$ Ésta era la continuidad o no de la unidad política del pueblo alemán, que se definía en la capacidad o incapacidad de decisión del pueblo como un todo. ${ }^{14}$ La amplitud de la libertad de prensa o las facultades del poder legislativo son cuestiones que vienen a continuación de una decisión concreta acerca de la propia existencia como unidad política. En esa situación, Schmitt aboga por reforzar las instancias institucionales con competencias para tomar resoluciones extraordinarias como vía para frenar los continuos actos de desestabilización de los partidos situados en los extremos, posición que tiene su correspondencia en el plano teórico con sus desarrollos de conceptos como «estado de excepción», «soberanía» y «dictadura» entre otros. La posición contraria, el liberalismo, se empecina en cambio con una serie de dispositivos que, con independencia de las intenciones de los actores involucrados, conducen indefectiblemente, según Schmitt, hacia un proceso de disolución. ${ }^{15}$ En el plano político es éste el principal motivo de su antiliberalismo: «liberal» es un modo de actuar y pensar política y jurídicamente que en el contexto de la crisis de Weimar conduce a la destrucción de la unidad política del pueblo alemán.

Este modo de pensar y de estar se mueve para Schmitt entre dos perspectivas cercanas y complementarias, pero que revelan cada una de ellas aspectos diferentes de la subjetividad liberal. En primer lugar, centradas en los textos escritos hasta la primera mitad de la década del '20, las ideas de Schmitt sobre el liberalismo se desarrollan con una fuerte presencia de los pensadores contrarrevolucionarios y ofrecen la imagen que ellos construyeron de la

13 Véase Schmitt 1923a: 47-50.

14 Véase Schmitt 1931: 110.

15 Uno de los ejemplos más significativos es el referente al desplazamiento liberal de la legitimidad por la legalidad. En la introducción a la segunda edición de 1968 de Legalidad y Legitimidad, Schmitt señala cómo la legalidad fue el «arma más poderosa» de Hitler para llegar al poder. Véase Schmitt 1931: 16-18. 
burguesía en el siglo XIX. La influencia de éstos, particularmente de Donoso Cortés, se percibe sobre todo en el lugar fundamental que ocupa el concepto de «discusión» como operación fundamental que constituye a la subjetividad liberal. En segundo lugar, aparece una caracterización del liberalismo que se construye a partir de la oposición a la teoría pluralista del Estado y al concepto de «compromiso» como operación fundamental del liberalismo en el contexto del fin de la distinción entre sociedad y Estado. En ambos casos, sin embargo, se mantiene el mismo sentido de las operaciones centrales de la subjetividad liberal: la dilación y su envés (anti)institucional, la negación del Estado como unidad soberana.

2.1 Schmitt retoma la caracterización que Donoso Cortés hace de la burguesía francesa durante la Monarquía de Julio como «clase discutidora» para situar a la discusión como operación constitutiva de la subjetividad liberal. Define así un criterio para comprender el liberalismo en su fundamento, que se construye sobre la imagen del liberalismo francés del siglo XIX acuñada por los contrarrevolucionarios. Esta caracterización no constituye para Schmitt un anacronismo ni aparece como insuficiente. ${ }^{16}$ En sus escritos de la primera mitad del '20, por el contrario, señala con claridad que aquella imagen de los contrarrevolucionarios es la más adecuada para comprender el liberalismo imperante en la Alemania de Weimar. Lo anacrónico no es para él la lectura del liberalismo con criterios del siglo XIX, sino el liberalismo mismo, tanto en su modo de actuar como en sus instituciones, empezando por la misma Constitución de Weimar. ${ }^{17}$ Al igual que el romanticismo, la subjetividad liberal se constituye a partir de la dilación indefinida de la decisión; de allí su incapacidad para pensar y actuar en el contexto conflictivo de la entreguerra que para Schmitt demanda una decisión capaz de poner fin al caos político y establecer un orden. Según su parecer, la vigencia del pensamiento contrarrevolucionario se encuentra precisamente en esta apelación a la decisión como única vía de resolución de una situación de conflicto político extremo, incluso con cierta indiferencia respecto del contenido de la decisión:

El significado actual de aquellos filósofos contrarrevolucionarios del Estado reside empero en su consecuente opción por la decisión. Ellos elevaron el momento de la

16 En su análisis de La situación espiritual-histórica del parlamentarismo actual, Eugenia Parise sostiene que una de las deficiencias del planteo schmittiano consiste en reducir la complejidad de los actores sociales que conforman la "clase media" a la burguesía del siglo XIX. Pero al afirmar esto pierde de vista la perspectiva schmittiana, ya que ésta no busca una descripción empírica del sujeto del liberalismo, sino la caracterización de su núcleo metafísico. Véase Parise 1995: 30-32.

17 «La constitución de Weimar es en cierto sentido algo póstumo. Ella realiza reivindicaciones, ideales y programas que fueron de actualidad en 1848» (Schmitt 1928b: 44). 
decisión a tal punto que finalmente suprimieron el pensamiento de la legitimidad, desde el cual habían partido. (Schmitt 1922: 69).

Schmitt remite al Ensayo sobre el catolicismo, el liberalismo y el socialismo de Donoso Cortés ${ }^{18}$ para mostrar el modo en que el liberalismo disuelve la necesidad de decidir en una eterna discusión. Allí el español señala al catolicismo y al socialismo como fuerzas políticas en pugna, una que sostiene la soberanía de Dios, otra la del Pueblo, en medio de las cuales se encuentra, sin decidirse, el liberalismo «que nunca dice afirmo ni niego y que a todo dice distingo» (Donoso Cortés 1851: 446). Con esta caracterización busca señalar el carácter inadecuado de la posición liberal frente a una situación de crisis política extrema (Donoso Cortés 1851: 449). Así lo expresa Schmitt:

En la esencia del liberalismo burgués se encuentra, según Donoso, el no decidirse respecto de esta lucha [entre catolicismo y socialismo], sino intentar entablar en su lugar una discusión. Define a la burguesía directamente como una «clase discutidora» [en esp. en el original]. Con lo cual queda juzgada, pues en ello reside su voluntad de evadir la decisión. Una clase que desplaza toda su actividad política a los discursos, la prensa y el parlamento no puede enfrentar una época de luchas sociales (Schmitt 1922: 64).

Esta última es la conclusión de Donoso Cortés que Schmitt aplica a su presente. No porque la «clase media» alemana del '20 sea idéntica a la burguesía francesa del siglo XIX en su composición social, sino porque, más allá de las inmensas diferencias que pueden encontrarse entre ambas, se constituyen para su intervención política a partir de la misma operación: la dilación de la decisión bajo la forma de la discusión. Si Schmitt llama «burguesía» al actor que pone en acto el dispositivo dilatorio de la discusión, no lo hace tanto como un recurso retórico o por la influencia de von Stein, Marx y Cortés ${ }^{19}$; tal nombre posee una fuerte carga polémica y apunta a indicar el núcleo antipolítico de tal actor. En efecto, la caracterización schmittiana es política antes que sociológica y se orienta a la comprensión de la subjetividad liberal y sus efectos para la situación política de Alemania, y no a un pretendido conocimiento «objetivo» de una determinada clase social.

Si bien el abordaje schmittiano del liberalismo se orienta a partir de una caracterización político-filosófica del mismo, no se agota en ella. Por el contrario, la definición del núcleo metafísico sirve como criterio ordenador que permite comprender desde un posicionamiento claro los 
distintos fenómenos que trata. En ese marco se inscriben sus ideas sobre el parlamentarismo. Schmitt no hace una mera descripción empírica del mismo, sino que lo aborda muñido de una clave interpretativa a partir de la cual podrá distinguir su sentido específico y distinguir qué le es propio y qué no, aún cuando en las opiniones al respecto e inclusive en la práctica concreta se mezclen los tantos. Al respecto Schmitt es particularmente claro: «La forma típica de aparición [typische Erscheinungsform] del liberalismo políticojurídico es el sistema parlamentario» (Schmitt 1928b: 46). El parlamento es pues, desde esta perspectiva, la institución de gobierno que se articula sobre principios liberales. En efecto, para Schmitt, «todos los órganos y normas específicamente parlamentarios cobran su sentido sólo por la discusión y la publicidad» (Schmitt 1923a: 5). Ambas habían sido recursos esenciales para la lucha contra el absolutismo en el siglo XIX y revelan, al igual que la división de poderes, el sentido específico del parlamento: es una institución orientada fundamentalmente al control del gobierno. La discusión como principio parlamentario se erige sobre la confianza en que el libre intercambio de opiniones produce espontáneamente la armonía (Schmitt 1923a: 46). De allí el retorno inevitable al principio antipolítico de la dilación: si la verdad es el resultado de un debate honesto, todo corte o interrupción será ilegítimo por principio. El tiempo no constituye una variable relevante al momento de la discusión y todo resultado de una determinación alcanzado antes del acuerdo armonioso de las partes será espurio. Como dinámica de gobierno, el parlamentarismo tiende entonces a la postergación indefinida de la decisión y sitúa al parlamento como principal contrapeso al carácter resolutivo del ejecutivo. La publicidad, por su parte, nace como una exigencia frente a los arcana rei publicae como principio de gobierno (Schmitt 1923a: 47-48). Se liga con el principio de la discusión en el punto en que la libre competencia de opiniones precisa que las mismas sean públicas y visibles para que cualquier ser dotado de razón pueda emitir su voz al respecto. En su desarrollo histórico la publicidad se desprende del conflicto concreto que le dio lugar y se vuelve una exigencia absoluta, válida por sí misma. En verdad, para mantener su intensidad polémica siempre se encontrará un resquicio al que oponerse. Eliminados los arcana del poder, se desconfía ahora de los hombres que traman secretos planes para beneficiar sus propios intereses, o de las instituciones políticas que por su propia dinámica corrompen a las personas y ocultan la verdad. En todo caso, la publicidad aparece para el parlamentarismo como un «correctivo absoluto» (Schmitt 1923a: 49) capaz de hacer frente a las arbitrariedades del poder.

Esta caracterización le permite a Schmitt distinguir el parlamentarismo de la democracia, en torno a lo cual gira el texto de 1923 (y sobre todo el 
prólogo de la edición de 1926) sobre el parlamentarismo. Esta distinción es fundamental porque permite comprender el mayor déficit de éste último, a saber, la falta de reconocimiento de la nueva situación política causada por el advenimiento de las masas como actor central y casi exclusivo de la vida política en Europa. La identificación de democracia y parlamentarismo es, en verdad, a los ojos de Schmitt, una simple remisión de los principios liberales al nombre democracia: se llama democráticos a aquellos gobiernos parlamentarios que sostienen la división de poderes y la necesidad del debate público. De ese modo, queda impensado lo específico de la democracia que, en su exacerbación a partir de la masificación de la política, precisa de nuevas formas de acción política. El parlamentarismo nació con relación a una disputa específica y un enemigo específico: la monarquía absoluta. Al intentar trasladarlo automáticamente a la situación alemana de la entreguerra, pierde su efectividad y se vuelve un recurso estéril para afrontar los desafíos de la democracia de masas. El motivo lo refiere Schmitt, nuevamente, a la operación específica del liberalismo parlamentario: la discusión. Sus presupuestos y condiciones de posibilidad han variado; y si esa fue una operación efectiva contra el absolutismo, nada puede hacer frente a los dispositivos de control y dirección de masas. La primera condición para que la discusión sea efectiva es que sea tomada en serio y no aparezca como una puesta en escena para conservar las formas. El soporte de la discusión es la confianza en la razón, en la verdad y, de allí, en la posibilidad de convencer al otro o de que el otro me convenza mediante argumentos racionales. Pero esta condición se ha visto avasallada por la democracia de masas que se impone mediante dispositivos de sugestión y producción de verdad muy diversos. En la mezcolanza de recursos audiovisuales, técnicos, psicológicos orientados a producir efectos en las masas, la discusión pierde su especificidad y deviene un recurso más sin especificidad alguna:

La situación del parlamentarismo es hoy tan crítica porque la evolución de la moderna democracia de masas ha convertido la discusión pública que argumenta en una formalidad vacía (Schmitt 1923a: 9).

En las prácticas de gobierno la discusión se vuelve negociación. Pero entonces ya no persigue ni la verdad ni la justicia, sino la conveniencia y el acuerdo de intereses (Schmitt 1923a: 8). Esto no constituye para Schmitt una impugnación de la negociación y exigencia de discusión, sino que da cuenta de la insuficiencia de ésta y de la necesidad de impulsar otras formas de gobierno específicas para la democracia de masas. 
2.2. Schmitt encuentra en la teoría pluralista del Estado una de expresiones más claras del liberalismo como «una teoría de la disolución o refutación del Estado» (Schmitt 1932a: 73). De acuerdo con ella, el Estado es una institución social más del complejo constituido por partidos políticos, sindicatos, agrupaciones de intereses, asociaciones civiles, la familia, las iglesias y demás organizaciones de la sociedad; no se encuentra ya por encima, sino junto a ellas (Schmitt 1930: 152). De ese modo pierde su núcleo político y se subsume en la heterogénea dimensión de lo social. Al hacerlo, el Estado queda equiparado a las restantes organizaciones sociales y pierde así el monopolio de la decisión. Frente a un conflicto ya no arbitra, sino que queda él también sujeto a la resolución que surja espontáneamente del libre juego social. Porque, desde el punto de vista de la teoría pluralista, ya no existe una instancia última de decisión, sino que ahora es cada individuo el que decide de acuerdo a sus relaciones de fidelidad y lealtad (a la familia, la empresa, la iglesia e incluso al Estado, pero puesto ahora al mismo nivel). Este desplazamiento de la decisión al individuo es, en verdad, una negación de la decisión en el sentido schmittiano de la palabra y en ello radica el carácter eminentemente liberal de esta teoría: ante la necesidad del trazado de directivas con relación a la vida política de un pueblo (en política exterior, economía, cultura, etc.) no hay una resolución posible; la dirección de la «sociedad» como un todo no puede ser determinada porque la decisión del conjunto se disuelve en una pluralidad inorgánica de voces. Al imposibilitarse de ese modo la decisión política, aquella que no sólo resuelve una situación de conflicto extremo, sino que configura y constituye la unidad de un pueblo, se pone en peligro, a los ojos de Schmitt, la continuidad del orden político existente. En los últimos años de la República de Weimar este peligro estaba representado fundamentalmente por el Partido Comunista y el Partido Nacional Socialista cuyos representantes insistieron, frente a un evidente (al menos para Schmitt) riesgo de disolución del Estado y la Constitución, en la defensa de los intereses particulares de sus partidos correspondientes sin atender al interés general del pueblo alemán como un todo.

La dispersión de las instancias de decisión vuelve imposible la comprensión del Estado como expresión de una voluntad unitaria. Frente a esto, la teoría pluralista concibe la institución del Estado como producto de un compromiso (Kompromiss). Con respecto a esta cuestión, Schmitt señala en primer lugar el vínculo de esta idea de compromiso como fundamento del Estado con la teoría dualista del Estado. Cuando no se comprende al Estado como una unidad cerrada en sí misma, sólo resta pensarlo como un compromiso entre partes que determinan el modo y forma de su existencia a través de contratos y acuerdos 
(Schmitt 1931: 60). Este punto de vista se manifestaba durante el siglo XIX en Alemania en la comprensión de la Constitución como un contrato cuyas partes eran el príncipe y el pueblo, el rey y las cámaras, el gobierno y el parlamento. Con el advenimiento de la democracia de masas, empero, se rompe aquella clara distinción y hace su entrada un concepto más amplio de compromiso que no se limita ya a aquellas figuras que permanecían dentro de la esfera del Estado. El compromiso en el que se sostiene la Constitución involucra ahora una pluralidad de partes entre las que se encuentran partidos políticos y asociaciones sociales con intereses de distinto tipo (económicos, religiosos, culturales). La construcción de la voluntad estatal ya no remite a una dimensión política-unitaria, sino justamente al compromiso de los distintos portadores del pluralismo estatal y las coaliciones que se constituyen de acuerdo al ámbito en el que se debe llegar a una resolución (política exterior, política económica, social o cultural). No se trata ya de las indefiniciones que se plasman en la Constitución en virtud de la concurrencia de diversos principios políticos y de la falta de definición por uno de ellos, sino del desplazamiento de la decisión hacia actores sociales no políticos (fundamentalmente económicos) ${ }^{20}$ que se produce en virtud de aquella indefinición. Cuando las posiciones e instancias constitucionales y políticas no son capaces de una resolución, entonces «otros poderes, sean legales o apócrifos, sea consciente o inconscientemente, se hacen cargo del rol del Estado y gobiernan por lo bajo, para decirlo de algún modo» (Schmitt 1931: 101). En la renuncia a decidir, el espacio de poder vacante nunca queda vacío. De este modo, sin embargo, se disuelve la unidad política del pueblo y se allana el camino para el advenimiento de otro tipo de orden en que el Estado ha sido colonizado enteramente por la sociedad. A este fenómeno, que para Schmitt no era ya una proyección, sino la situación efectiva de la gran mayoría de los Estados industriales, lo llamó «Estado total». ${ }^{21} \mathrm{El}$ Estado como compromiso entonces conduce al aplazamiento indefinido de la decisión mediante la multiplicación indeterminada de las instancias de decisión: si todos deciden por sí mismos, entonces no hay decisión común.

La negación de la decisión política inscripta en el concepto de compromiso es referida también por Schmitt en su Teoría de la Constitución para referirse a la Constitución de Weimar. Le asigna allí «carácter de compromiso» en la medida en que, respecto de diversas cuestiones centrales, hace del aplazamiento

20 Sobre el devenir del Estado pluralista en un Estado económico y en una policracia donde domina lo económico sobre lo político, véase Schmitt 1931: 91-94.

21 Sobre el «Estado total» Schmitt 1931: 73-91. Sobre el carácter «totalitario» del pluralismo Schmitt 1932c: 115. 
de la decisión su procedimiento más característico. El compromiso consiste en ese contexto en la búsqueda de una «formula que satisfaga todas las exigencias contradictorias y deje indecisa en una expresión anfibológica la cuestión litigiosa misma» (Schmitt 1928a: 54). Así, si bien en última instancia Weimar se constituye como una democracia constitucional burguesa y rechaza la alternativa socialista (que se presentaba en ese entonces bajo la forma soviética), no excluye la introducción de diversos principios de distinto corte, relativos a las «leyes constitucionales», que la vuelven una Constitución «mixta».22 En ella conviven aspectos liberales con otros socialdemócratas o de antiguo cuño que no siempre son compatibles entre sí. Frente a esta convivencia de elementos difícilmente conciliables, el aplazamiento indefinido de una decisión que resuelva la cuestión en favor de uno u otro se vuelve así el dispositivo más corriente. En el contexto de la Teoría de la Constitución, Schmitt refiere a esta idea de compromiso para señalar que en la ley no hay contenida voluntad alguna y que toda la mezcolanza de principios jurídicos y políticos contenidos en la Constitución de Weimar sólo tiene sentido sobre la base de una decisión del pueblo alemán en su conjunto a favor de la democracia constitucional y, lo que para Schmitt es más fundamental, en contra de una República socialista de Consejos como la que impulsaban los espartaquistas (Schmitt 1928a: 57). Si la de Weimar es una Constitución, lo es porque hay una voluntad política unitaria que la sostiene, éste es su supuesto, aún cuando se encuentre repleta de formulas dilatorias.

En este punto se visualiza el carácter de compromiso de la Constitución de Weimar no ya respecto de cuestiones puntales, sino tomada en su conjunto: ella está partida en dos. La primera parte, que delinea los rasgos fundamentales de un sistema parlamentarista, formalista y liberal, y la segunda que es, en realidad, «una segunda parte contrapuesta a la primera, heterogénea respecto a la que organiza un Estado legislativo parlamentario; en suma, una segunda Constitución» (Schmitt 1932c: 58). En efecto, la segunda parte se ordena como un sistema jurídico con principios no sólo diversos, sino incluso contradictorios con los que ordenan la primera parte. De hecho, la segunda parte introduce una serie de principios materiales sustantivos que rompen con la neutralidad axiológica de la primera. Sin embargo, el antagonismo más fuerte no se encuentra allí, sino en los principios ordenadores de cada parte, que da

22 Éste es el sentido de «mixto» en el contexto de la Teoría de la Constitución (Schmitt 1928a: 53). En «El Estado de derecho burgués» refiere esta idea de status mixto a todo Estado burgués y avanza un paso más al señalar el sentido de la «mixtura»: los principios opuestos contenidos entre sí se neutralizan mutuamente a favor de la libertad individual del burgués. Véase Schmitt 1928b: 46. 
nombre al libro donde se abordan estas cuestiones con mayor profundidad: por un lado el principio de legalidad, por el otro, el de legitimidad. ${ }^{23}$ De allí que la Constitución de Weimar, aún cuando contenga importantes determinaciones políticas, lleva inscripta la postergación liberal de la decisión en su estructura misma, ya que elude definirse respecto del sistema que la ordena (legalidad parlamentaria o legitimidad plebiscitaria). Esta indefinición nodal es lo que la vuelve fuente de inestabilidad política y del debilitamiento de la unidad política del pueblo alemán. Porque, en el contexto del pluralismo estatal, la falta de decisión respecto de estos principios los vuelve a ambos obsoletos como principios ordenadores y los reduce a una función meramente instrumental al servicio de los intereses en pugna:

La legalidad y la legitimidad se convierten entonces en instrumentos tácticos, de los que cada cual se sirve conforme le resulte ventajoso en el momento, arrojándolos a un lado cuando se dirijan contra él mismo, y tratando cada una constantemente de arrancárselos de la mano al otro. Ni la legalidad parlamentaria, ni la legitimidad plebiscitaria, ni ningún sistema concebible de justificación, pueden sobrevivir a semejante degradación en herramienta técnico-funcionalista. También la Constitución se disuelve en sus elementos y en sus posibilidades de interpretación contradictorios, y ninguna ficción normativista de «unidad» impedirá que cada uno de los grupos en pugna se apodere de aquel fragmento o palabra de la Constitución que le parezca más apropiado para derribar al partido contrario, también en nombre de la Constitución. La legalidad, la legitimidad y la Constitución, en vez de impedir la guerra civil, sólo contribuyen a exacerbarla (Schmitt 1932c: 116).

En otro pasaje similar de El custodio de la Constitución, parece afirmar (Schmitt emplea en este caso el potencial) no ya la posibilidad de una guerra civil, sino su efectividad, al menos en estado larvado:

Si el Estado no fuese nada más que este sistema pluralista, entonces sería en verdad
sólo un compromiso continuo; su constitución sería un contrato entre complejos
sociales de poder que construyen y basan el sistema pluralista sobre la base de la
frase pacta sunt servanda; los contrayentes retendrían su obra, la Constitución, en
sus manos, permanecerían como amos del contrato constitucional, el cual podrían
modificar tal como lo habían constituido y persistirían entre sí como magnitudes
políticas autónomas. Lo que quedaría de unidad estatal sería entonces (como en toda
alianza y contrato) el resultado de una alianza acordada con reservas existenciales.
«El contrato entonces sólo tiene el sentido de un acuerdo de paz entre los grupos
pactantes, y un acuerdo de paz posee siempre, quiéranlo así o no los partidos, una
relación con la posibilidad de la guerra, por más lejana que sea.» ${ }^{24}$ Eso sería, cuando
las agrupaciones decisivas entre amigo y enemigo se determinan internamente en vez 
de externamente, una guerra civil. ¿Qué sería en una situación tal «Estado» y qué el «todo» de la unidad política de un pueblo? (Schmitt 1931: 141-142).

En efecto, que el Estado y la Constitución sean compromisos, supone que no hay una subjetividad común, sino que los que pactan mantienen una «reserva existencial» respecto de todo lo que pueda ser decidido estatalmente. En ese sentido, todos los pactantes son, potencialmente, enemigos. Si el liberalismo pluralista conduce a esta posibilidad es justamente porque posterga indefinidamente la decisión política a partir de la cual se destruye aquella reserva mediante la institución de una relación de representación. Para Schmitt el liberalismo es, en su núcleo mismo, desestabilizador. Porque no se trata solamente de su escasez de recursos para hacer frente a situaciones excepcionales, sino que, al preservar lo particular frente al Estado, no puede dejar de afirmar, al mismo tiempo, la posibilidad real de la guerra civil. Sobre todo en el contexto de la sociedad de masas en el que ha desaparecido la distinción entre Estado y sociedad y, en consecuencia, los antagonismos sociales y económicos ya no tienen sobre sí un criterio superior capaz de limitarlos. Desde esta perspectiva, no hay orden sin política y cuando reina la paz, ello se debe al Estado y la política, y nunca a los diversos mecanismos liberales de control del poder. Lo que Schmitt percibe cada vez más claramente es que los actores sociales desligados de una articulación política, pero activos en su intervención a través de acuerdos y compromisos, sólo ven en la política un recurso para proteger y fomentar sus propios intereses. El hecho de pensarla de ese modo revela la aspiración íntima de estos actores a disponer de todas las ventajas del poder político sin asumir ninguno de sus peligros. ${ }^{25}$ Pero, si nada se debe a la política y sólo es posible pensar la responsabilidad con relación a los propios intereses privados-económicos, entonces no hay ya unidad, sino sólo fragmentación y guerra civil latente.

25 Los actores de este uso meramente instrumental de lo político que busca sustraerse al elemento de riesgo que porta son llamados por Schmitt «poderes indirectos» y surgen junto con sus reflexiones acerca del Estado pluralista. Véase por ejemplo Schmitt 1931: 64. Pero esta figura tiene un desarrollo posterior en su texto de 1938, sobre la figura del Leviatán en Hobbes. Allí también se encuentran relacionados con la idea de pluralismo y de evasión del riesgo político, pero con vistas a pensar el fracaso del Leviatán como símbolo político capaz de contenerlos y la consiguiente decadencia de la estatalidad moderna. Véase Schmitt 1938: 123-141. Sobre este tema ver Dotti 2002. Allí el autor señala cómo en el contexto de 1938 Schmitt también incluye entre los poderes indirectos a los organismos paraestatales del nacionalsocialismo. El texto sobre el Leviatán expresaría así una forma de compromiso (quizás tenue, pero real) contra el nazismo. 
La negativa a reconocer un criterio autónomo de lo político une en lo más íntimo al romanticismo y al liberalismo en su común antipoliticidad. Pero mientras que el romanticismo articula dicha negativa mediante una estetización general de la realidad, el liberalismo lo hace mediante la resignificación de conceptos políticos mediante otros de orden ético o económico. Así, por ejemplo, la lucha se vuelve ahora competencia o discusión, el Estado se torna sociedad, el pueblo es ahora masa de consumidores, y el dominio y el poder se convierten en propaganda y manipulación de masas (Schmitt 1932a: 100). El dispositivo es el mismo: desconocer la especificidad de lo político y su subsunción bajo otras esferas que permiten la neutralización - conceptual - de la conflictividad como presupuesto y de la necesidad de decisión y forma representativa que se sigue de ella. Es en este sentido que no puede haber una «política liberal, sino siempre únicamente una crítica liberal a la política» (Schmitt 1932a: 98). Así como el romántico no podía intervenir políticamente, sino sólo acompañar emotivamente un suceso político, la crítica es el modo liberal de ese acompañamiento. Los liberales «yo discuto» y «yo contrato», por un lado, y el romántico «yo poetizo», por otro, son distintas formas de aparición del «yo difiero» constitutivo de la subjetividad antipolítica. La lúcida comprensión de estas figuras por parte de Schmitt no se desarrolla a partir de un mero interés científico por el conocimiento, sino por motivos políticos. A través de ellas Schmitt puede comprender y posicionarse en la conflictiva situación alemana del período de entreguerras. $\mathrm{Su}$ voz en ese contexto no tiene matices: frente a la crisis nada pueden hacer las discusiones y compromisos, es la política la que debe ponerse al frente. Cuando una época demanda una decisión, su dilación sólo puede conducir a la fragmentación y disolución.

\section{Referências}

Joseph W. Bendersky (1983), Carl Schmitt. Theorist for the Reich, Princeton, Princeton University Press, 1983.

Juan Donoso Cortés (1851), Ensayo sobre el catolicismo, el liberalismo y el socialismo. Citado según la edición de las Obras Completas, editadas por J. Juretschke, Madrid, B.A.C., 1946, pp. 347-551.

Jorge E. Dotti (2002), «¿Quién mató al Leviatán? Schmitt interprete de Hobbes en el contexto del nacionalsocialismo», Deus Mortalis, n ${ }^{\circ}, 2002$, pp. 93-190.

Jorge E. Dotti (2005), «Ménage à trois sobre la decisión excepcional. Kierkegaard, Constant y Schmitt», Deus Mortalis, n²4, 2005, pp. 303-379.

Carlo Galli (1996), Genealogía della politica. Carl Schmitt e la crisi del pensiero politico moderno, Bologna, Il Mulino, 1996. 
Günter Maschke, «Drei Motive im Anti-Liberalismus Carl Schmitts», Carl Schmitt und die Liberalismuskritik, K. Hansen/H. Lietzmann (Hrsg.), Opladen, Leske + Budrich, 1988, pp 55-79.

Eugenia Parise, Carl Schmitt. La difficile critica del liberalismo, Napoli, Liguori Editore, 1995.

Carl Schmitt (1919), Politische Romantik, München/Leipzig, Duncker \& Humblot, 1919. Se cita según la traducción al español de L. A. Rossi y S. Schwarzböck, Romanticismo político, Quilmes, UNQ Ediciones, 2001.

Carl Schmitt (1922), Politische Theologie. Vier Kapitel zur Lehre von der Souveranität, München/Lepzig, Duncker \& Humblot, 1922. Se cita según la séptima edición de 1996.

Carl Schmitt (1923a), Die geistesgeschichtliche Lage des heutigen Parlamentarismus, München/Leipzig, Duncker \& Humblot, 1923. Se cita según la traducción al español de T. Nelson y R. Grueso, Sobre el parlamentarismo, Madrid, Tecnos, 1996. Esta edición incluye el importante prefacio a la edición de 1926.

Carl Schmitt (1923b), Römischer Katholizismus und politische Form, Hellerrau, Jakob Hegner, 1923. Se cita según la traducción al español de C. Ruiz Miguel, Catolicismo y forma política, Madrid, Tecnos, 2000.

Carl Schmitt (1928a), Verfassungslehre, München/Lepzig, Duncker \& Humblot, 1928. Se cita según la traducción al español de F. Ayala, Teoría de la Constitución, Madrid, Alianza, 1996.

Carl Schmitt (1928b), «Der bürgerliche Rechtstaat», Die Schildgenossen, Jg. 1928 (pp. 127-133). Se cita según la edición de Günter Maschke, Staat, Großraum, Nomos. Arbeiten asu den Jahren 1916-1969, Berlin, Duncker \& Humblot, 1995, pp. 44-54.

Carl Schmitt (1930), «Staatsethik und Pluralistischer Staat», Kantstudien, Band 35, Heft 1 (pp. 28-42). Se cita según la tercera edición de Carl Schmitt, Positionen und Begriffe im kampf mit Weimar - Genf - Versailles 1923-1939, Berlin, Duncker \& Humblot, 1994.

Carl Schmitt (1931), Der Hüter der Verfassung, Tübingen, J.C.B. Mohr (Paul Siebeck), 1931. Se cita según la cuarta aparecida por la editorial Duncker \& Humblot en el año 1996.

Carl Schmitt (1932a), Der Begriff des Politischen, München/Lepzig, Duncker \& Humblot, 1932. Se cita según la traducción al español de R. Agapito, El concepto de lo politico, Madrid, Alianza, 1999

Carl Schmitt (1932b), «Schußrede vor dem Staatsgerichthof in Leipzig in dem Prozeß Preußen contra Reich». Se cita según la tercera edición de Carl Schmitt, Positionen und Begriffe im kampf mit Weimar - Genf-Versailles 1923-1939, Berlin, Duncker \& Humblot, 1994.

Carl Schmitt (1932c), Legalität und Legitimität, München/Lepzig, Duncker \& Humblot, 1932. Se cita según la traducción al español de J. Díaz García, Legalidad y legitimidad, Buenos Aires, Struhart \& Cía., 1994. 
Carl Schmitt (1938), Der Leviathan in der Staatslehre der Thomas Hobbes. Sinn und Fehlschlag eines politischen Symbols, Hamburg, Hanseatische Verlaganstalt, 1928. Se cita según la traducción al español de A Attili, El Leviatán en la doctrina del Estado de Thomas Hobbes, México D.F., Universidad Autónoma Metropolitana, 1997. 